\title{
LARGE SCALE MODELLING OF DAMAGE AND FAILURE OF NUCLEAR GRAPHITE MODERATED REACTOR Ahmadreza Farrokhnia ${ }^{1}$, Andrey P Jivkov ${ }^{2}$
}

${ }^{1} \mathrm{PhD}$ student, University of Manchester, Manchester, M13 9PL, ahmadreza.farrokhnia@ manchester.ac.uk

${ }^{2}$ Professor, University of Manchester, Manchester M13 9PL, andrey.jivkov@ manchester.ac.uk

\begin{abstract}
The UK Advanced Gas-Cooled reactors (AGRs) have cores made of graphite bricks with dual functions: as structural elements of the core, providing space for and separating fuel and control rods; and as moderator of the nuclear reaction. Nuclear graphite is a quasi-brittle material, where the dominant mechanism for failure is cracking. While cracking of isolated bricks is expected due to operation-induced changes in graphite microstructure and stress fields, these could be tolerated as far as the overall structural function of the core is maintained. Assessment of the whole core behaviour has been previously done with whole scale models where bricks have been considered as rigid body elements connected by elastic-brittle springs. This approach does not allow for the realistic assessment of the stresses in the bricks and associated brick cracking. Reported here are results from an ongoing project, which addresses this shortcoming. The proposed model uses deformable bricks with appropriate interactions, allowing for physically realistic whole core analysis. The results are focused on the damage that a graphite moderated reactor develops during a life cycle, how this affects the behaviour of the whole core, and how changes in bricks' behaviour impacts the core integrity. The proposed methodology is a major step towards high-fidelity assessment of AGRs' fitness for service, required for supporting continuous safe operation and life-extension decisions.
\end{abstract}

\section{INTRODUCTION}

The Advanced Gas-Cooled reactors (AGR) in the UK use graphite as a moderator and also as a structural component. The reactor core contains three different types of interlocking graphite moderator bricks: fuel bricks, interstitial bricks and filler interstitial bricks as shown in Fig. 1. The bricks are stacked vertically on top of each other, with the entire core consisting of 12 layers of bricks. Each layer contains 323 fuel bricks and 293 interstitial and filler interstitial bricks. The gaps in the bricks create vertical channels for fuel assemblies, control rods and coolant flow. The entire structure is connected via a system of loose keys and keyways, which allow the core to expand and contract during service. A layer of Upper Neutron Shield of graphite bricks covers the assembly. The whole system is kept laterally stable using a system of restrain rods and beams, centralising brackets and Warwick links tied to restrain rings (Ahmed, et al., 1986).

During the reactors life cycle, different fuel bricks undergo dimensional changes at different rates due to temperature and irradiation gradients, e.g. bricks located in central layers are irradiated at a faster rate. The structural integrity of bricks is critical to the safe reactor operation, because cracked bricks can lead to core distortion and potentially to channels misalignment. This could cause blockages that prevent insertion or extraction of fuel and control rods. The whole core behaviour due to dimensional changes has been a subject of a number of past works. Due to the large number of bricks, these works have been mostly based on models with rigid-body bricks connected by spring elements representing the keys. In such case, all mechanical effects are assigned to the springs: stiffness, friction, damping and damage/failure. While 

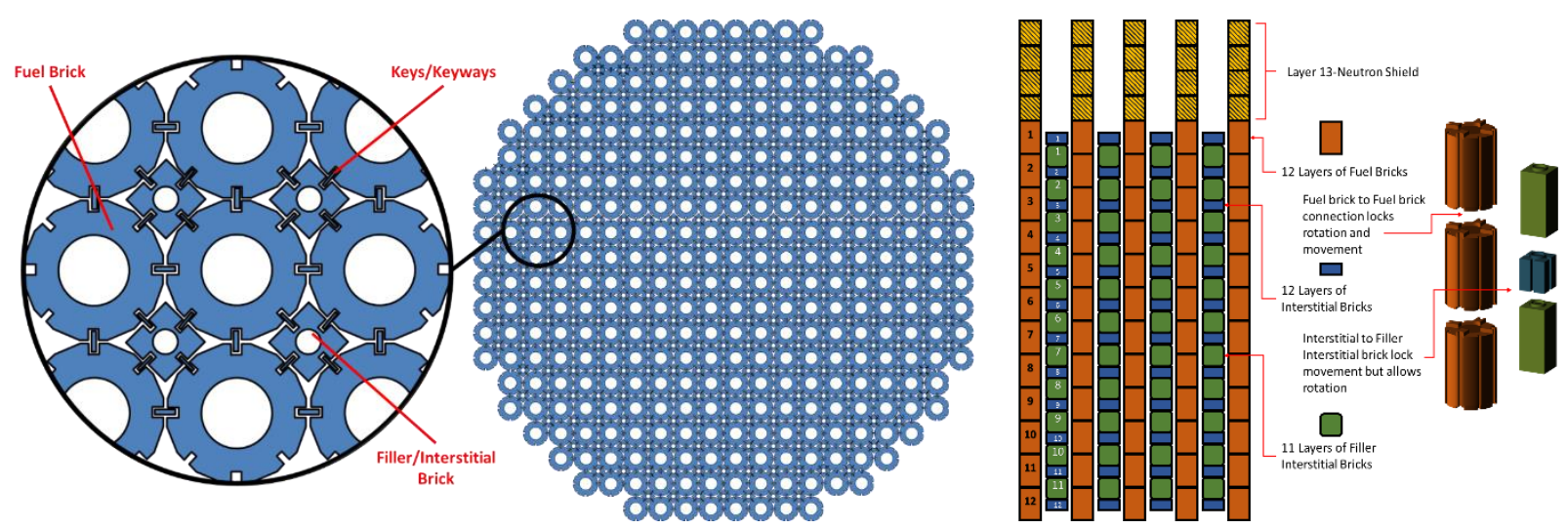

Figure 1. Layout of one layer of graphite moderated reactor.

the approach allows for calculating load transmission or impacts between the bricks (Duncan \& Kralj, 2007), it has a major limitation - deformation, damage and fracture of the bricks cannot be analysed. As a consequence, the effect of bricks' damage and failure on the core behaviour cannot be investigated.

The aim of the project reported in this work is to gain better understanding of temperature and irradiation effects on a graphite reactor core by developing a more realistic model with deformable bricks and bespoke interactions. The model presented allows for investigations of how the changes of graphite properties throughout the course of a reactor's lifespan affect the whole core geometry and integrity. In particular, this development will allow for improved assessment of the core fitness-for-purpose towards its projected end of life and inform life-extension decisions

\section{REACTOR CORE MODEL}

A finite element model of the whole core has been developed using deformable brick elements and surface interactions. Thus far computational power has been a major limiting factor for constructing such a large model. One of the difficulties lies in the definition of individual contact surfaces. With a whole model containing 18504 individual bricks, each tessellated into continuum finite elements, over 90000 different interacting surfaces exist in the model. Via a purpose-built Python script for ABAQUS, only surfaces in direct contact were defined, reducing substantially the computational power required. These surfaces were grouped together allowing for a whole-scale model to be created. The model contains initial gaps of $10 \mathrm{~mm}$ between the individual bricks, as per design specification.

While graphite is quasi-brittle material, it is assumed to be linear elastic for the purposes of this work. However, the Young's modulus $E$ is made dependent on temperature and dose, while the Poisson's ratio is kept constant. Two operational loads causing dimensional changes are considered: temperature and irradiation. These are applied separately to the model. Each load induces non-mechanical strains, a thermally-induced strain, $\varepsilon^{t h}$, and an irradiation-induced strain, $\varepsilon^{i r}$, which modify the gaps between the bricks. When bricks get in contact due to gap closure, further expansive strains cause deformation of these bricks with associated stresses.

The temperature distribution within the core is assumed constant from start to end of the reactor's lifecycle (outages not considered). The temperature varies between the different layers, with the central bricks having a higher temperature than the bricks at the top and bottom of the reactor. Within each fuel brick in a particular layer the temperature decreases by around $50^{\circ} \mathrm{C}$ from the inner edge to the outer edge. These variations are illustrated in Fig. 2. 

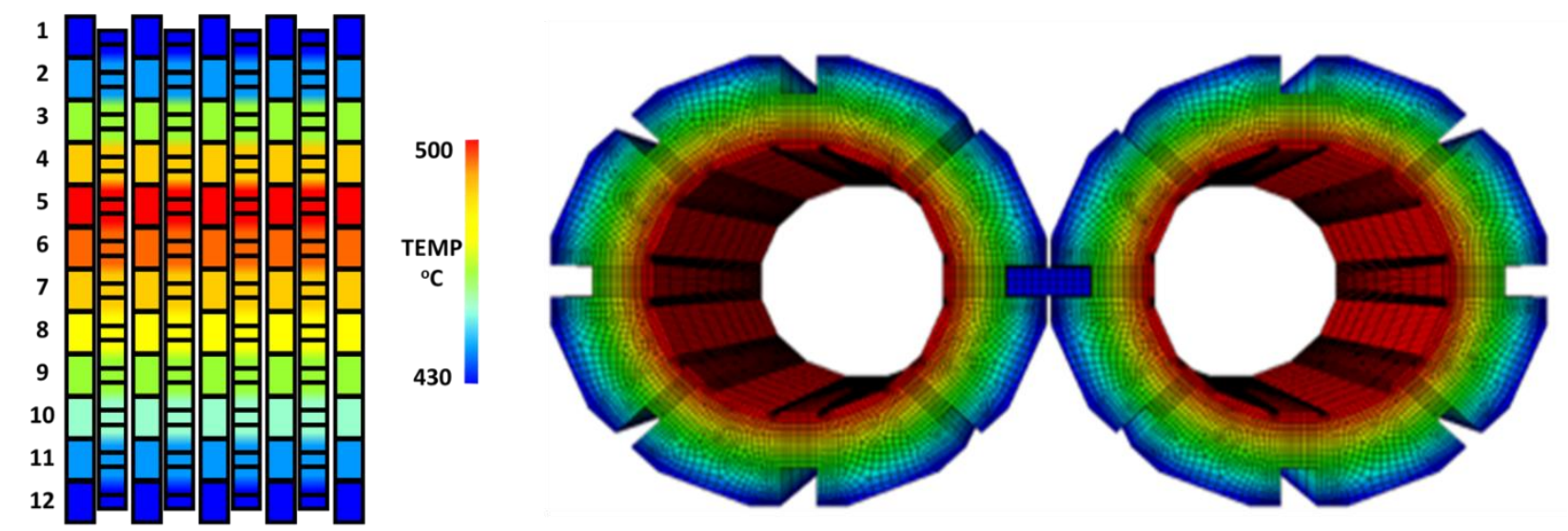

Figure 2. Illustration of temperature fields in the core and inside bricks

The temperature variation between layers and between brick surfaces used in the present work are shown in Fig.3. Notably, the highest temperature is not at the central layer, but at layer 5 of the core. This bias is due to the air flow through the reactor passing from layer 12 to layer 1, causing a distortion in the distribution of the temperatures. The temperature field is assigned by a Python script to the elements of individual bricks, assuming linear variation across brick thickness. Thermal strains result from temperature gradients, as described by Eq. (1) (Kyaw, et al., 2014), where the coefficient of thermal expansion, $\alpha$, used in the present work was $4.39 \times 10^{-9}$ ( $\mathrm{Li}$, et al., 2007). This value remained constant throughout the reactor's life cycle.

$$
\varepsilon^{t h}=\alpha \Delta T
$$

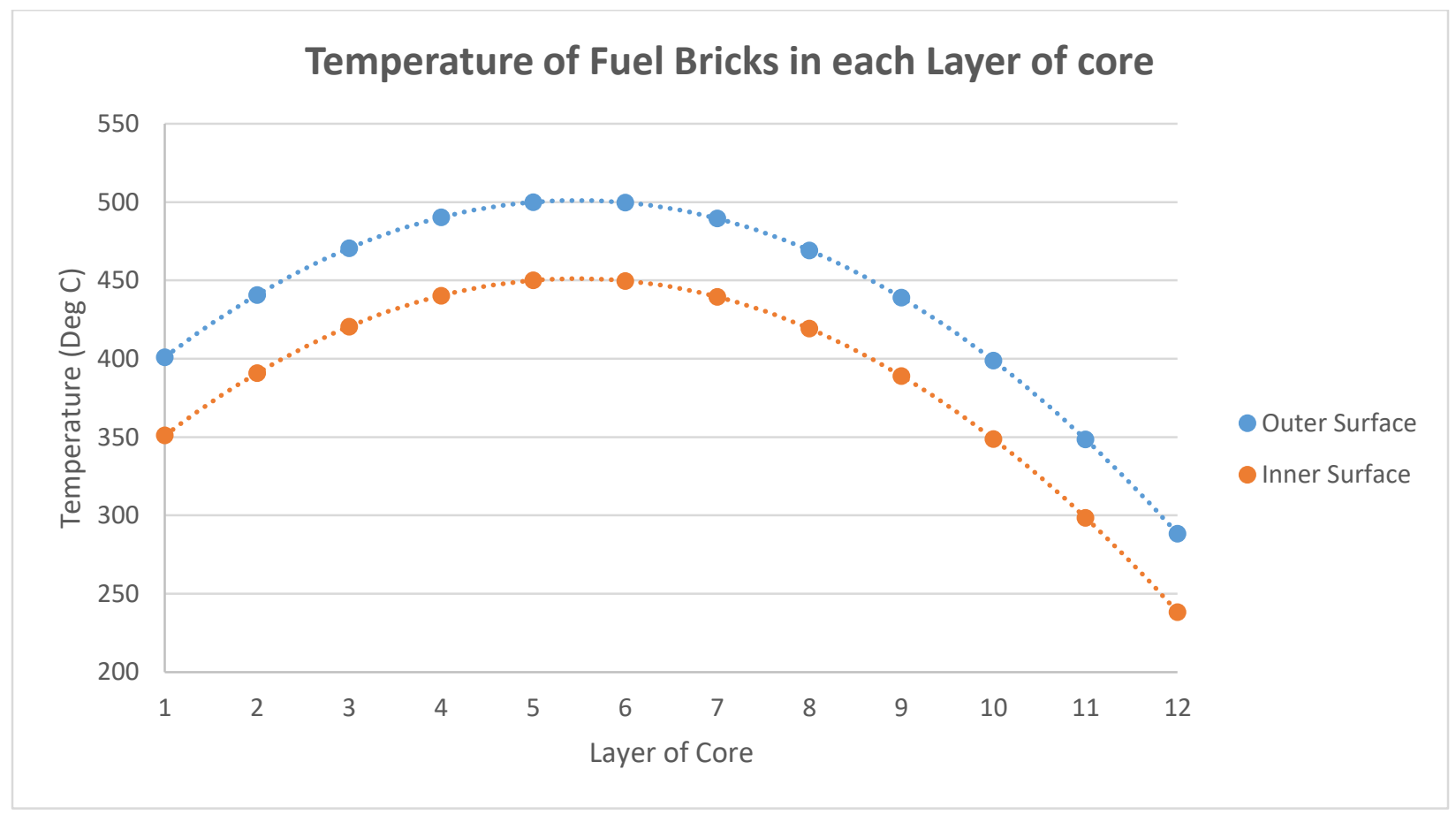

Figure 3. Temperature variation between layers and bricks surface 
The effects of irradiation on a single brick have been modelled and discussed in previous works, e.g. (McLachlan, et al., 1996). It has been found that as graphite bricks irradiate, they firstly shrink, then expand beyond their original dimensions, a process illustrated in Fig. 4. As fuel bricks' interiors receive higher dosages, the inner surfaces shrink at a faster rate than the outer surfaces. After 30 years of service the dose on the inner surface of the brick is approximately $200 \times 10^{20} \mathrm{n} / \mathrm{cm}^{2}$ while the dose on the outer surface is $112 \times 10^{20} \mathrm{n} / \mathrm{cm}^{2}$. This creates a potential for bore cracking, where tensile stresses exist close to the centre of the brick and compressive stresses exist on the outside. The effect is reversed later in the bricks life with generation of compressive stresses at the inner surface and tensile stresses at the outer surface. These changes cause stress concentration at key ways and could lead to crack initiation. The cracks created due to bricks expansion can join up with cracks created during the initial shrinking resulting in brick failure.
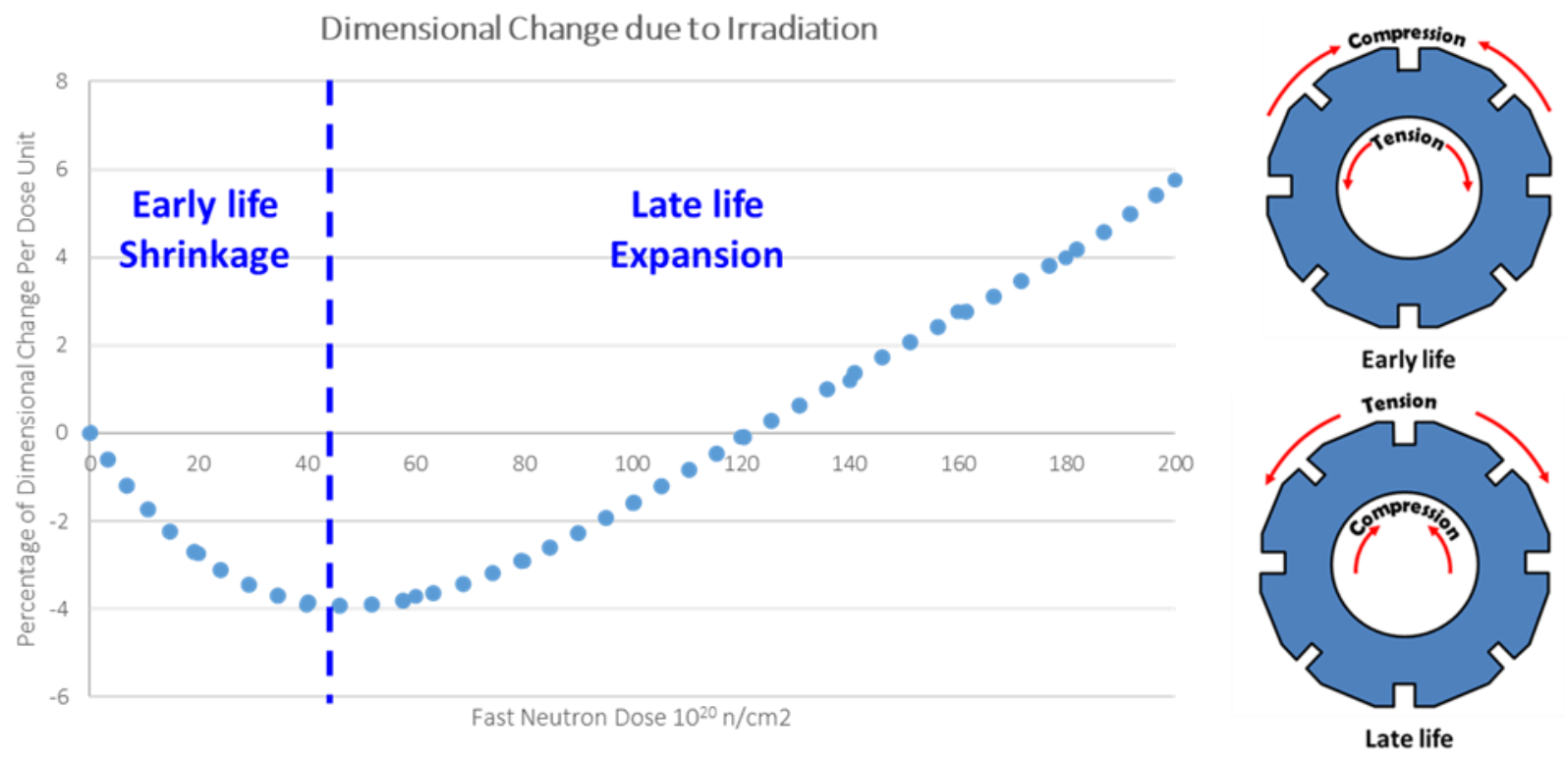

Figure 4. Effects of irradiation-induced dimensional changes on brick stresses.

Keyway cracking is of greatest concern to operators, as multiple brick failures can lead to compromising the whole keying system or multiple channels (Zou, et al., 2006). Such scenarios have been examined by a series of experiments with single un-irradiated graphite moderator bricks and corresponding finite element analyses replicating the conditions in a real reactor (McLachlan, et al., 1996). The results showed good agreement between the predicted failure strength and available experimental data. Furthermore, fast cracking at one keyway is anticipated to trigger a secondary crack at another, potentially opposite keyway, leading to brick disintegration. This phenomenon, known as prompt secondary cracking has been investigated in detail by dynamic fracture analysis, with results clearly confirming the anticipation (Crump et al., 2017; Crump et al., 2019).

Considering the data in Fig. 4, the irradiation strain $\varepsilon^{i r}$ can be expressed as a function of fast neutron dose $\gamma$ using a $4^{\text {th }}$ degree polynomial, Eq. (2), where $A_{0}, A_{1}, A_{2}$ etc. are coefficients derived from the respective polynomial fits given in Table 1 .

$$
\varepsilon^{i r}=A_{0} \gamma^{4}+A_{1} \gamma^{3}+A_{2} \gamma^{2}+A_{3} \gamma+A_{4}
$$

Similarly, to the thermal loads, the irradiation loads are modelled with a constant dose for each layer, variable dose between the layers, and variable dose between inner and outer brick surfaces. The dose 
distribution in the core is shown in Fig 5. Equations (1) and (2) can be combined to provide a value for the total strain induced by particular temperature and irradiation dose in any finite element of any brick:

$$
\varepsilon=\left(\alpha \Delta T+A_{0} \gamma^{4}+A_{1} \gamma^{3}+A_{2} \gamma^{2}+A_{3} \gamma+A_{4}\right)
$$

Table 1: Polynomial coefficients for calculating irradiation-induced strains $\left(A_{i}\right)$ and Young's modulus

\begin{tabular}{lcccccc} 
& \multicolumn{7}{c}{ variation with irradiation dose $\left(\mathrm{B}_{\mathrm{i}}\right)$ and temperature $\left(\mathrm{C}_{\mathrm{i}}\right)$} \\
Coefficient & $\mathbf{A}_{\mathbf{0}}$ & $\mathbf{A}_{\mathbf{1}}$ & $\mathbf{A}_{\mathbf{2}}$ & $\mathbf{A}_{\mathbf{3}}$ & $\mathbf{A}_{\mathbf{4}}$ & \\
Value & 0.15 & -4.1228 & 41.792 & -135.79 & 0.6446 & \\
Coefficient & $\mathrm{B}_{0}$ & $\mathrm{~B}_{1}$ & $\mathrm{~B}_{2}$ & $\mathrm{~B}_{3}$ & $\mathrm{~B}_{4}$ & $\mathrm{~B}_{5}$ \\
Value & $9.397 \mathrm{E}-7$ & $4.610 \mathrm{E}-4$ & $6.923 \mathrm{E}-2$ & -2.6907 & $2.793 \mathrm{E} 1$ & $1.399 \mathrm{E} 4$ \\
Coefficient & $\mathrm{C}_{0}$ & $\mathrm{C}_{1}$ & $\mathrm{C}_{2}$ & $\mathrm{C}_{3}$ & $\mathrm{C}_{4}$ & $\mathrm{C}_{5}$ \\
Value & $8 \mathrm{E}-07$ & 0.0038 & 6.0112 & 2253.5 & 241532 & $1 \mathrm{E} 10$
\end{tabular}

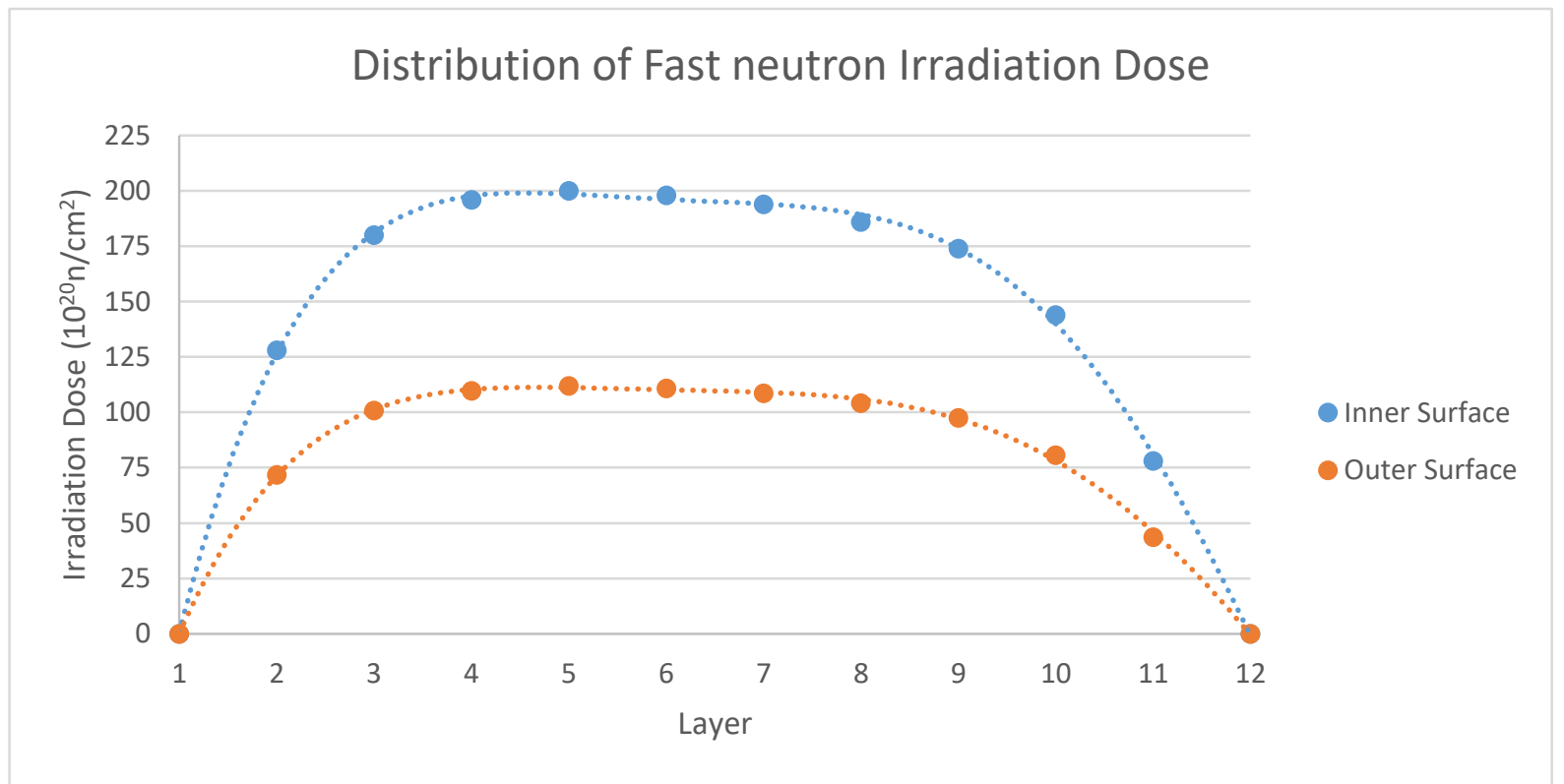

Figure 5. Distribution of fast neutron irradiation dose within reactor core.

Computationally, the effects of temperature and irradiation dose are imposed by the local changes of Young's modulus they incur. Young's modulus varies with the dose rate $\gamma$, can be approximated by a $5^{\text {th }}$ degree polynomial given by Eq. (4) (Li, et al., 2007), where $B_{0}, B_{1}, B_{2}$ etc. are coefficients derived from the respective polynomial fits given in Table 1 .

$$
E^{i r}=B_{0} \gamma^{5}+B_{1} \gamma^{4}+B_{2} \gamma^{3}+B_{3} \gamma^{2}+B_{4} \gamma+B_{5}
$$

Similarly, the Young's modulus dependence on temperature $T$ can be approximated by a $5^{\text {th }}$ degree polynomial given by Eq. (5) (Maruyama, et al., 1987) where $C_{0}, C_{1}, C_{2}$ etc. are coefficients derived from the respective polynomial fits given in Table 1.

$$
E^{T}=C_{0} T^{5}+C_{1} T^{4}+C_{2} T^{3}+C_{3} T^{2}+C_{4} T+C_{5}
$$

The effects of irradiation and temperature on Young's modulus are illustrated in Fig.6. 


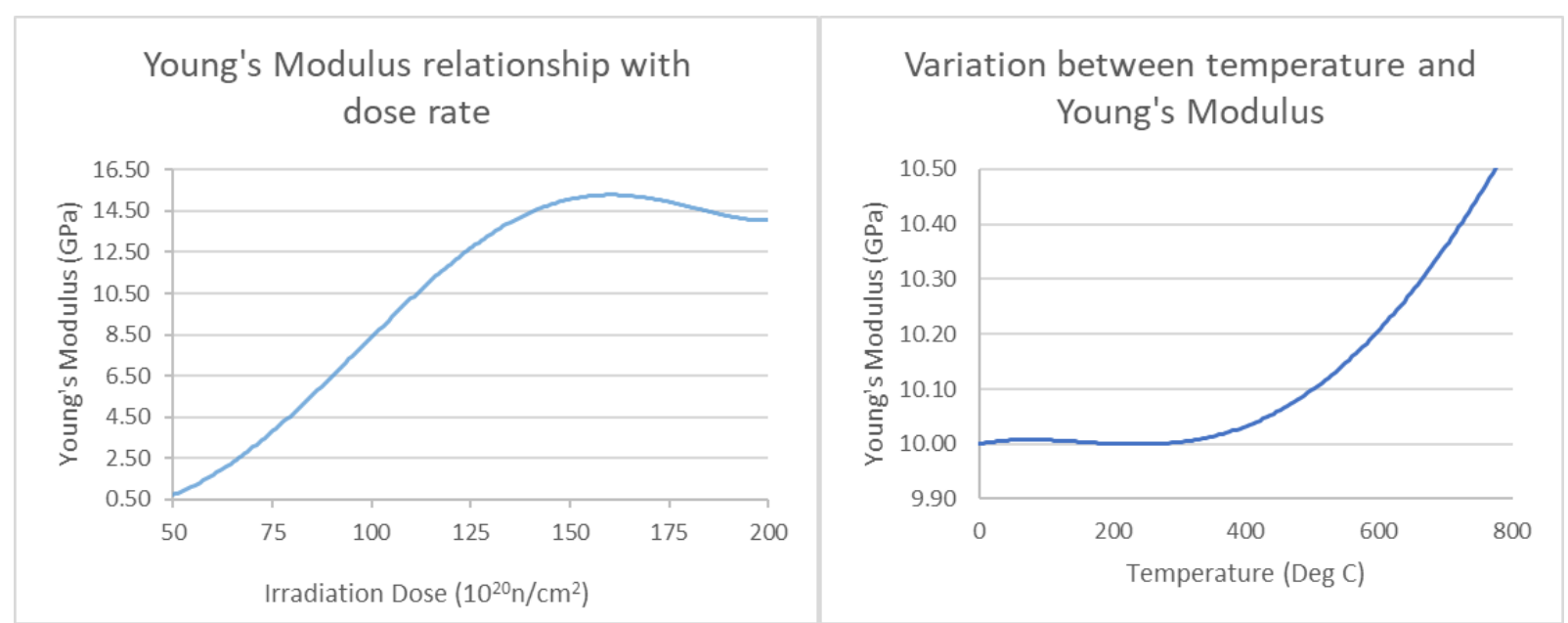

Figure 6. Shows how the value for young's modulus varies with dose rate (left) and temperature (right).

\section{RESULTS AND DISCUSSION}

A whole scale model containing all the bricks and keys is displayed in Fig.7, where a solution due to gravitational forces is used for illustration. The inclusion of all gaps in this model makes the analysis due to thermal and irradiation loads computationally expensive at this stage. Therefore, a smaller model is used to develop confidence in the modelling approach used to represent the gaps between the bricks, before moving analysis back onto a full-scale model. The smaller model contains 120 fuel bricks, and a total of 430 bricks and is shown in Fig. 8 . The gaps between the various bricks have been modelled by deformable continuum finite thickness cohesive elements. The stiffness of these elements is significantly lower than that of the graphite bricks.

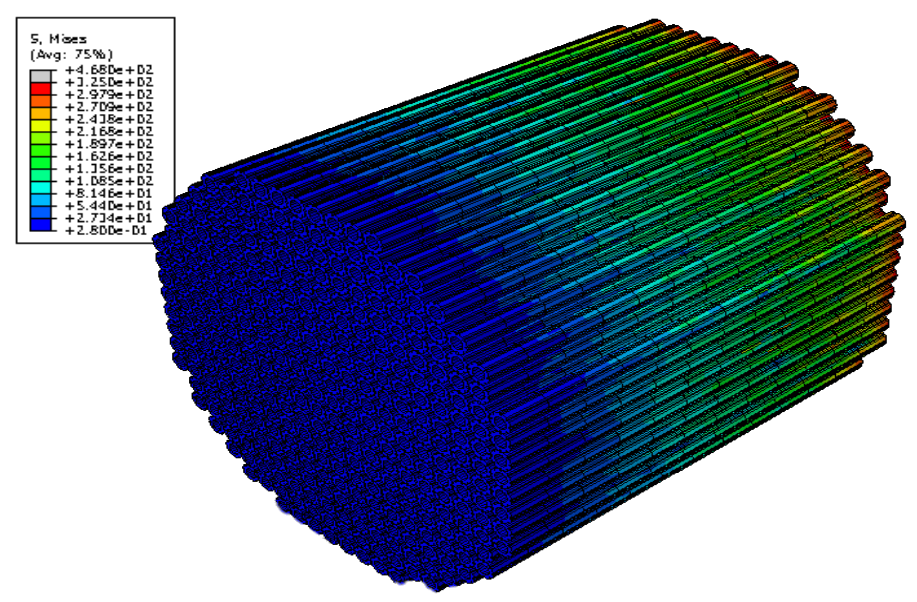

Figure 7. Stresses due to gravity on whole scale model

Due to the reduced number of bricks the loads shown in the previous section could not be applied to this model in principle. However, for the purposes of illustration, the same distribution of thermal loads 
and irradiation loads is applied here as shown in Fig. 9. It is noted that the load gradients in this case are larger than in the full-scale model, which may lead to larger stress gradients between layers.

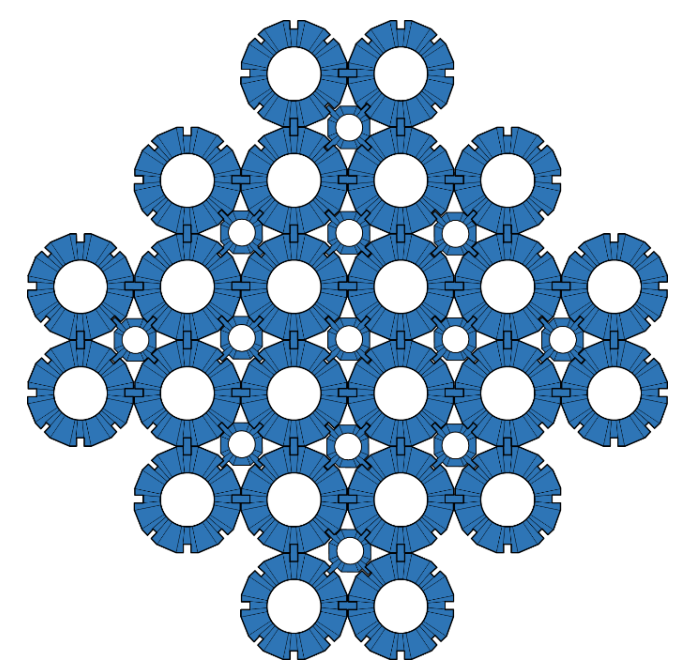

Figure 8 . A 6 by 6 by 5 model generated to test approach used.

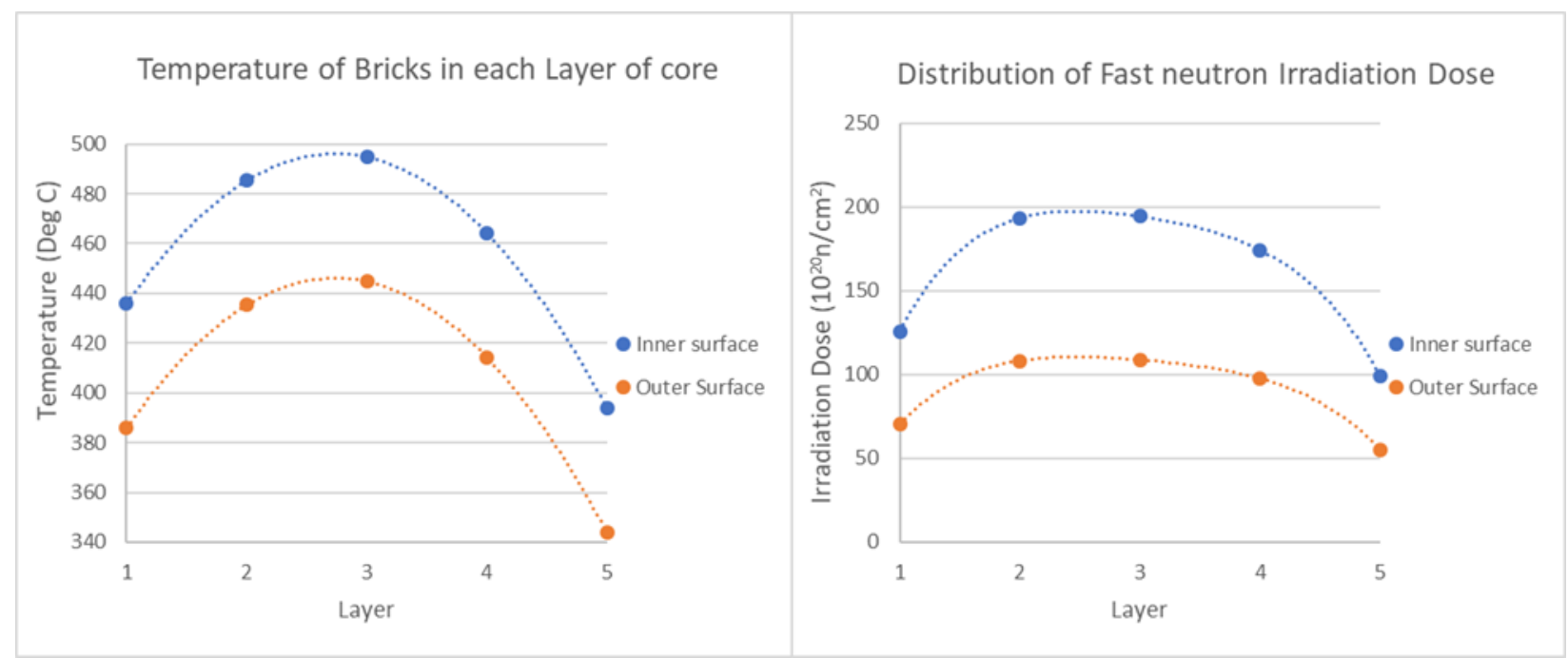

Figure 9: Thermal (left) and irradiation dose (right) loads applied to a 6 by 6 by 5 model

The initiation of cracking in graphite is controlled by the maximum principle stress. An estimate for the energy release rate, $G$, upon cracking can be made by assuming that the maximum principal stress, $\sigma_{I}$, acts over a material-dependent distance or length scale, $d$ (a crack-jump). It is assumed here that the material length scale equals the mean particle size in Gilsocarbon, which is estimated to be $914 \mu \mathrm{m}$ (Morrison, et al., 2016). Cracking occurs when the energy release rate reaches a critical value - the fracture energy, $\mathrm{G}_{\mathrm{c}}$. From the fracture toughness and elastic modulus of Gilsocarbon, the fracture energy is estimated to be $200 \mathrm{~J} / \mathrm{m}^{2}$ (Mostafavi, et al., 2013). This provides an estimate for the critical value of the maximum principal stress of $0.22 \mathrm{MPa}$. 
Finite element analysis of the model is used to access the evolution of the maximum principal stress at brick keyways. The results for all brick types are analysed and the evolutions of the most stressed bricks of each type are given in Fig. 10. Specifically, the fuel brick with the largest maximum principal stress displays a final value of $0.64 \mathrm{MPa}$. This brick is located in column 2, row 3 and on layer 3 of the system. The largest maximum principle stress was found to occur in one interstitial brick, 1.6 MPa, as shown in the figure. Assuming that the maximum dose a brick will receive after 30 years of service is $200 \times 10^{20} \mathrm{n} / \mathrm{m}^{2}$, comparing to the maximum stress value required for a crack to occur to the maximum principle stresses found through finite element analysis, it is found that an interstitial brick will crack first after 19 years of operation, followed by a key after 22 years, and a fuel brick after 23 years. The filler interstitial bricks will be the last bricks to show signs of cracking at 30 years. Comparing Fig.10 with Fig.4, it is clear that the maximum principal stress increases when the bricks begin to expand beyond their original size, indicating correlation between the expansion of the brick and stress value seen in the keyways of the bricks. The reason for the sudden increase in stress is the initiation of contact between bricks, which according to the analysis here is after 19 years of service.

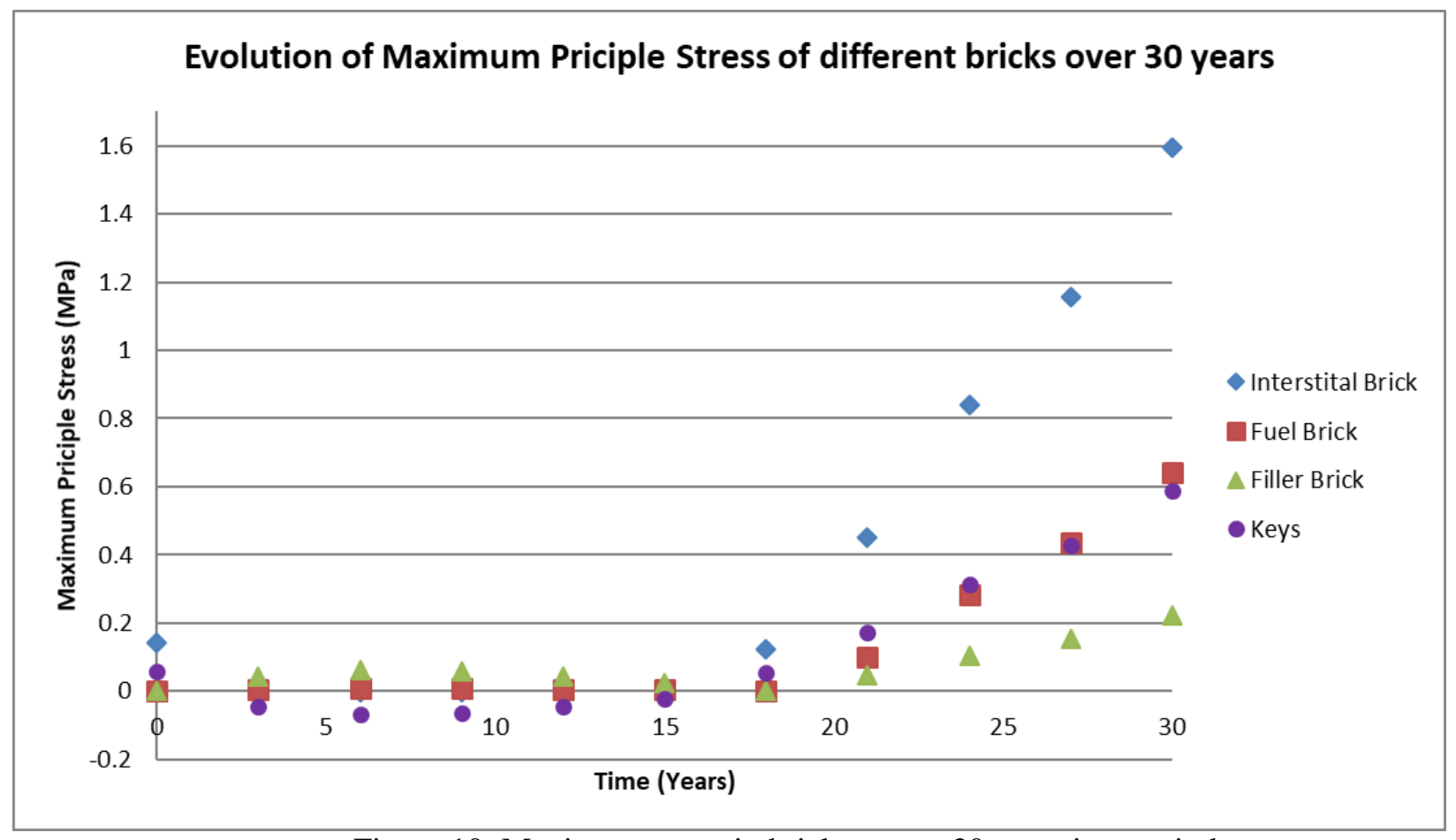

Figure 10: Maximum stress in bricks over a 30-year time period

Fig.11 shows the percentage of elements where the calculated maximum principle stress surpasses the $0.22 \mathrm{MPa}$ calculated as the requirement for a crack to occur. Fig.10 shows that the interstitial bricks fracture first and will reach a higher peak maximum principle stress, however Fig.11 indicates a larger number of fuel bricks will fail over the 30-year operational time. In addition, Fig. 11 shows that the interstitial bricks begin to fail at a linear rate beyond the $19^{\text {th }}$ year where the first crack occurs, however the fuel bricks will fail exponentially following the $23^{\text {rd }}$ year where the first crack occurs. This can be explained with the lack of irradiation load on the interstitial bricks in comparison to the fuel bricks, where stresses are caused by both the dimensional changes due to irradiation and the bricks coming into contact with each other. 


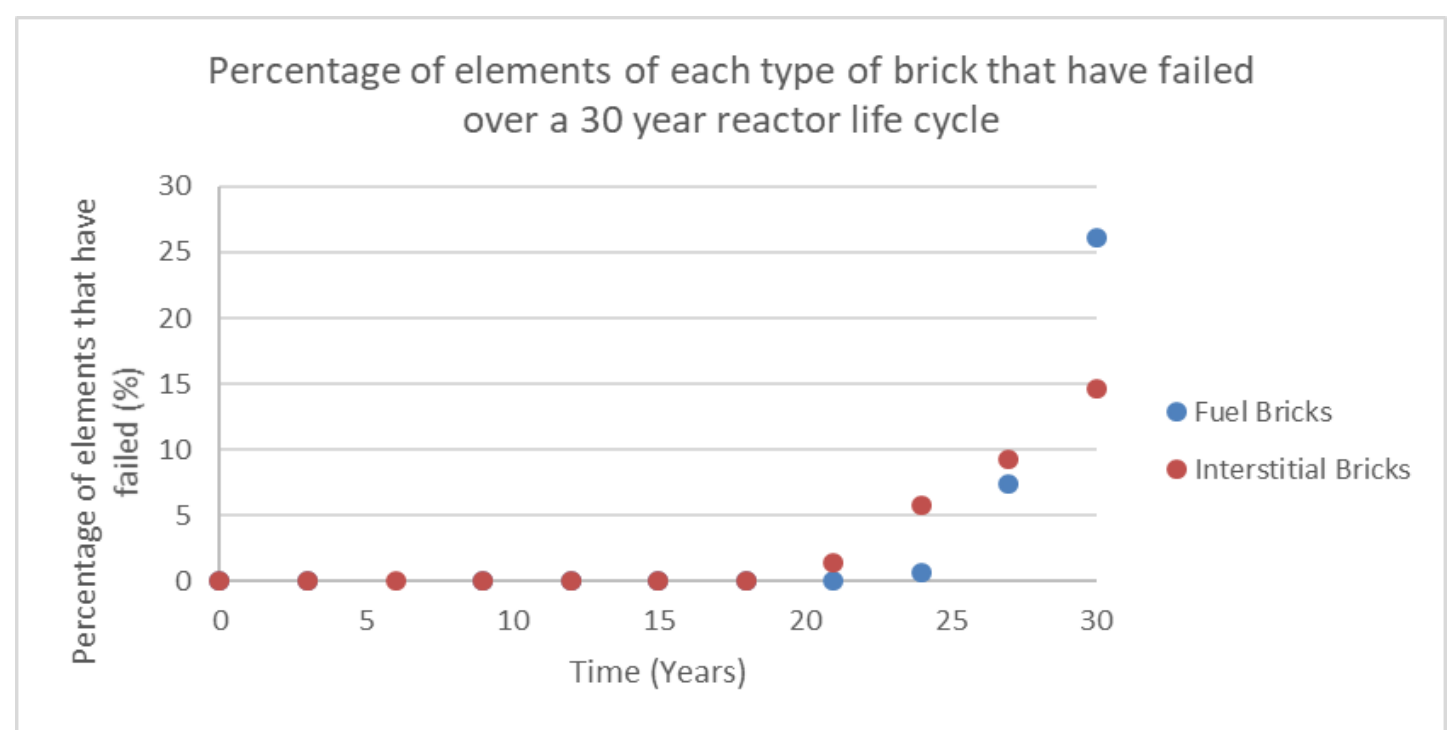

Figure 11: Percentage of elements for each brick that have failed in the model

In order to ensure the plant can remain operational, the channels must remain sufficiently aligned for fuel assemblies and controls rods to both enter and exit the rector as shown in Fig.12. By measuring the displacement of each channel (shown with a red line in Fig.12) and comparing this to the original length the tortuosity of each channel can be found. Within the 6 by 6 by 5 model, it was discovered that the channel with the highest tortuosity was 2-2 which had a value of 1.0016. This indicates that all the channels alignment was not compromised after 30 years of service. However, due to only having 5 layers the assessment of tortuosity is only indicative; analysis of full-scale model is expected to provide a closer estimate.

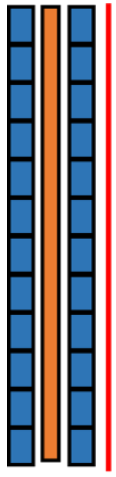

A

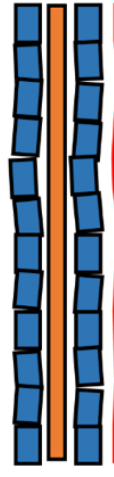

B

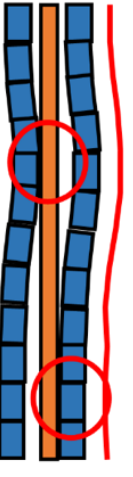

C
A- Initial position of bricks

B- After small movement

of bricks but fuel assembly

still accessible

C- Fuel assembly becomes

jammed due to the high

tortuosity of bricks

Figure 12: How tortuosity of each channel is measured

\section{ONGOING WORK}

While so far it has been shown that the method used will be able to produce result of practical importance, a full-scale model remains to be developed where the gaps between the bricks are included. The inclusion of these gaps is vital in the understanding of when bricks will fracture and how they will affect each other. It was shown with Fig.10 that only when expansion occurs, the stresses in the bricks begin to rise, and without such gaps the stresses would be significantly higher, significantly sooner, creating unreliable results. Once a full-scale model is developed, life cycles load condition will be placed on the bricks. This will be completed by applying dimensional changes caused by irradiation and thermal loads. From investigation of the data gathered, it will become clear how irradiation induced changes to individual bricks affects the integrity of the whole core. 


\section{CONCLUSION}

The creation of a realistic whole scale model of AGRs moderator is of significant industrial importance. The complexity of developing such a model lies with the large number of graphite bricks in the model, and the interactions between them. In order to overcome this issue Python scripting has been employed alongside ABAQUS to develop a realistic model. Up to now a full-scale model has been developed which does not include gaps between the bricks. A smaller model, which does include gaps between the bricks, is used instead to demonstrate the capability of the approach. This will be extended to the full-scale in the near future.

While the results displayed in this work indicate that the onset of cracking is after 19 years of operation in interstitial bricks, followed by faster cracking in fuel bricks, these outcomes cannot be claimed to be relevant to a real reactor, because of the size of the model analysed. The approach proposed however creates confidence that it is possible to develop a full-scale model and analyse the development of cracking in the core throughout the duration of the rector's life cycle. With the addition of damage properties, it will be possible to also investigate how damaged bricks influence the surrounding bricks and the integrity of the entire matrix of bricks. Ultimately, assessments of the whole core fitness-for-service will be made with higher confidence.

\section{ACKNOWLEDGMENTS}

\section{REFERENCES}

Abrahamson, J., 1973. The surface energies of graphite. Carbon, 11(4), pp. 337-362.

Ahmed, K. M., Parker, J. V. \& Proffitt, D. E., 1986. Seismic response of the advanced gas cooled reactor core. Nuclear Engineering and Design, 94(1), pp. 67-92.

Duncan, B. \& Kralj, B., 2007. Seismic Modelling of an AGR Nuclear Reactor Core. Bristol, Atkins. Kyaw, S. T. et al., 2014. Modelling Crack Growth within Graphite Bricks due to Irradiation and Radiolytic Oxidation. Procedia Materials Science, Volume 3, pp. 39-44.

Crump, T., Jivkov, A.P., Mummery, P., Ferte, G., Tran, V-X., 2019. Analysis of dynamic fracture and fragmentation of graphite bricks by combined XFEM and cohesive zone approach. International Journal of Pressure Vessels and Piping, 171, pp. 117-124.

Crump, T., Ferté, G., Mummery, P., Jivkov, A.P., Martinuzzi, P., Tran, V-X, 2017. Dynamic fracture effects on remote stress amplification in AGR graphite bricks. Nuclear Engineering and Design, 323, pp. 280-289. Li, H., Fok, A. S. \& Marsden, B. J., 2007. An analytical study on the irradiation-induced stresses in nuclear graphite moderator bricks. Journal of nuclear materials, 372(2-3), pp. 164-170.

Maruyama, T., Eto, M. \& Oku, T., 1987. Elastic modulus and bend strength of a nuclear graphite at high temperature. Carbon, 25(6), pp. 723-726.

McLachlan, N. et al., 1996. A Probabilistic approach to assessing AGR core life. Nuclear Energy, 35(1), pp. 15-23.

Morrison, C. N., Jivkov, A. P., Vertyagina, Y. \& Marrow, T. J., 2016. Multi-scale modelling of nuclear graphite tensile strength using the site-bond lattice model. Carbon, Volume 100, pp. 273-282.

Mostafavi, M., McDonald, S. A., Mummery, P. M. \& Marrow, T. J., 2013. Observation and quantification of three-dimensional crack propagation in poly-granular graphite. Engineeing Fracture Mechanics, Volume 110, pp. 410-420.

Zou, Z., Fok, S. L., Marsdem, B. J. \& Oyadiji, S. O., 2006. Numerical simulation of strength test on graphite moderator bricks using a continuum damage mechanics model. Engineering Fracture Mechanics, 73(3), pp. 318-330. 